\title{
Children's Problem Behaviour and Their Effect on Class Activities in Early Childhood Centres of Effutu Municipality
}

\author{
S. Oppong Frimpong and M. Gyapong
}

\begin{abstract}
The purpose of the study was to examine the prevailing children's problem behaviour and their effects on class activities in pre-schools in Effutu Municipality of Ghana. The study adopted the concurrent mixed methods design. Data were collected through a semi-structured interview schedule and questionnaire. The stratified random sampling technique was used to aid the selection of 15 schools from the Municipality. Simple random sampling was used to select 45 respondents from schools to respond to the questionnaire and purposive sampling was used to sample 15 participants for the qualitative data. The quantitative data was analysed using frequencies and percentages while the qualitative data were analysed thematically. It emerged from the study that the predominant types of children's problem behaviour which teachers encountered were; aggression, non-compliance, destructiveness, refusal to take instruction and intentional destruction of property. Among the effects of the problem behaviours the study revealed were inattention from class activity thereby impeding participation in academic activities; breeding of social exclusion from peers, the behaviour challenges resulting in violent actions (behaviour) and other misbehaviour against others. Based on the findings, it is recommended that Effutu Municipal Assembly, Winneba Educational Directorate and the headteachers from the selected schools for the study should organize programmes in collaboration with the early childhood unit on how to cope, prevent and deal with problem behaviour and its effects to ease the burden of parents and teachers and also help the learners to benefit from their academic activities. Early childhood education teachers should also make changes to their lesson delivery strategies by asking learners to read out loud, and by actively engaging the supposed disruptive learners more often to improve their concentration and class participation.
\end{abstract}

Index Terms - classroom activities, early childhood centres, effects, problem behavior

\section{INTRODUCTION}

One of the important elements of an effective of the classroom manager is a teacher who is supposed to have read wide on what triggers problem behaviours in children. Thompson [1] found that the most common children's problem behaviour is that they do not follow directions from a teacher or caregiver. ${ }^{1}$ In the circle time, for example, children like to talk constantly with their peers and not to listen to a teacher or a caregiver. The reasons children behave in such a way is because they cannot understand what teachers are teaching which may be because they do understand the words used by teachers. Other than talking

Published on January 13, 2021

S. Oppong Frimpong, Department of Early Childhood Education, University of Education, Winneba, Ghana

(corresponding email: sofrimpong@uew.edu.gh) with peers, children also like to put their hands or other body parts on their allies to distract them [2].

Additionally, hitting, kicking, catching, or poking other peers is common among children [2]. According to [3] children often like to test limits and standards and to split down the precepts set out by teachers or caregivers, to find out how teachers or caregivers would respond to such behaviours. [2] who stated that children sometimes walk far from their seats to find out how teachers will react to that behaviour. Furthermore, throwing tantrums and arguing is the most common problem behaviour in the classroom, especially at the preschool level [4]. In the research by [5] 58 teacher trainees undergoing training in preschool classes listed the problematic behaviors they encountered as talking, carelessness, indifference, aggression, or rough and scurrilous talking. Excessive activity refers to oppressive, careless and non-ceasing behaviors. Excessively active/hyperactive children have shown behavioral problems, such as communication problems, academic failure and aggression [6]. Epidemiological studies in the U.S. using standardized diagnostic criteria suggest that, frequency of hyperactivity and inattentive behaviors in the preschool period is about 3-4\% [7]. In the study conducted in Sydney, Australia by [8], it was determined that excessively active children failed to be attuned to their class. One of the behavior problems found in preschool children in Sydney was their being full of anxiety and fear ([8].

To emphasize the state of the situation in Ghana, a report by Strengthening Transparency, Accountability and Responsiveness, Ghana [9] conducted a study on children's problem behaviour and identified some symptoms which include difficulty in completing task which affect their grades adversely, short attention span, and need to have questions and directions repeated. Others included difficulty delaying gratification, fidgeting, a rush through chores or tasks, and difficulty remaining on task. The research suggests that children who exhibit aggressive behaviors including such non-social behaviors as insult, teasing, threatening may frequently be exposed to refusal, exclusion by his/her peers [10]. The study found that, there was no data on pupils with problem behaviour. Early recognition, assessment and management of this condition can redirect the education and psychosocial development of most pupils with these problems and this study could help in such direction. This study may be used to help in the early detection of problem behaviours among early childhood pupil's, as assessment is focused at the earliest classes. 
The study seeks to explore the problem behaviours that are often exhibited by some Ghanaian children within the Effutu Municipality and the effects of those behaviours on classroom activities in early childhood centres of the said municipality.

\section{LITERATURE REVIEW}

The related literature review focuses on types of children's problem behaviour and effects of children's problem behaviour.

\section{A. Problem Behaviours in Early Childhood}

Problems behaviour among children is acknowledged as a serious mental health issue. Externalizing behaviour problems is one of two primary forms of child/children maladaptive behaviours. It is a distinguished independent construct in children and adolescent psychopathology [11]. Externalizing problems may be more prevalent among children who are predisposed by psychosocial risk, and males may be more prone to externalize than females [12].

The term externalizing behaviour is employed to key out less severe disruptive and destructive behaviours [13]. The classification includes argumentation and nonconformity with adult directives, hostile behaviours toward others, impulsivity, and hyperactivity [14]. These are broadly thought to be the precursor to more serious behaviours. Hinshaw [15] conceptualized externalizing behaviours as those established in the form of aggression, delinquency, and hyperactivity. The literature expands the category to include negative, hostile, refusal to take instructions, destructiveness and defiant behaviours which characterize relations with adults, particularly parents and teachers [16].

Goddard [17] conducted a study to explore the factors associated with aggressive behaviour in children. The findings of the study showed that, aggressive behaviour displayed by children is a growing and common problem of concern. The study found that aggression was associated with behaviours that lead to harm; such as behaviours intended to harm even if the attempt fails. Such behaviours included when a person attempts to shoot, but misses a human target and that aggression is a prominent feature in childhood, often labelled as tantrums in some cases. The study even concluded that violence is aggression, but not all aggression is violence.

Children with aggression exhibit frightening and threatening behaviour like (young child kicks, bites or fights with other children). This has been indeed, supported by a research which has shown that aggressive children are at high risk of later serious and chronic violent behaviour and suggests that there is stability in aggression from adolescence to middle age [18]. Nagin and Tremblay [19] found that aggressive behaviour at age six predicted self-reports of violence and serious delinquency during adolescence among boys, nearly one-half of all children who exhibited moderate levels of aggression at age six showed notably lower levels of aggression by ages 10 to 12 .

Kopystynska, Paschall, Barnett, \& Curran, [20], contends that elements of the destructive activity of a person appear in early childhood and the early ages of children destruction could be very close or similar to vandalism. These destructive activities of children affect classroom learning. In a study by [21] on vandalism from childhood to adolescence, it was found that basic vandal activity originates in the early stages and may be characterized by destructive actions such as throwing objects or items and damaging classroom materials.

\section{B. The effects of problem behaviours on classroom activities}

While externalizing behaviours often present themselves as children age, such difficulties often are comorbid with academic difficulties and internalizing problems as well [22]. Many types of behaviour disrupt children learning. These include talking out of turn, being out of the seat without permission, not paying attention and distracting other children by making noise or touching them [23]. It has been suggested that children exhibiting disruptive behaviours may have difficulties learning new skills [24]. Finn, Pannozzo \& Voelkl [25] also state that teachers can make a big difference in their classrooms by responding to disruptive behaviour by making changes to the lessons, asking students to read out loud, calling on certain students more often to improve academic growth. Thomas and Guskin [26] and [27] examined disrupted behaviours in young children between the ages of 0-4 using Diagnostic Classification 0-3, which is an addition to the DSM-IV-TR (2000) used for young children.

Regnier [28] found that seventh grade children with behaviour disorders are not only more frequently absent and tardy than their non-behaviour disordered counterparts, but also are less likely to complete their homework and more likely to earn failing grades. Furthermore, children with behaviour disorders are more likely to exhibit inappropriate behaviours in the classroom and in turn lead their teachers to discuss those problems more often at team meetings. The discussion suggests that challenging behaviours in the preschool years or early years adversely impacts children's learning: by extension, such problems seem likely to result in difficulties in the child's future.

Moreover, [29] report that children who displayed attention and behaviour problems and were generally regarded as "hard-to-manage", continued to demonstrate behavioural as well as academic difficulties in elementary school. It also has been suggested that children exhibiting challenging behaviours may have difficulties learning new skills [24]. Richman, et al. [30] found that young boys who displayed behavioural difficulties until age eight were more likely to perform lower on measures of reading ability and general intelligence; however, such deficits were not observed in girls.

Based on the literature above, it could be suggested that, pupils with externalizing behaviour present to others as aggressive and disruptive, hyperactive, defiance (overt behaviours). The teacher and other peers in the classroom are more likely to be distracted by pupils who are overtly disruptive and obtrusive; hence, classrooms with high levels of externalizing behaviours are more likely to affect individual pupils or interfere with classroom activities as well as having immediate and lasting effects on individual academic performance [31]

\section{Problem statement}

Despite the recent trends of teacher education programs to increase training in the area of classroom management and of school to correct teachers ${ }^{\text {ee }}$ deficiencies in classroom management skills, teachers continue to struggle with the reality of the effects of children problem behaviours and it's 
classroom management issues. However, more concern is the fact that both novice and experienced teachers still struggle in the area of raising learners "performance in pre-schools due to the behaviour problems children display and the treats those behaviours pose to classroom activities.

According to the [32], problem behaviours such as aggression and disruptive classroom behavior in early childhood contribute to low school performance and inadequate peer relations. However, a study conducted by [33] in the Effutu Municipality seemed to suggest that attention has not been paid to the children's problem behaviour cases in early childhood centres within the said municipality. This suggest that much has not been done regarding the prevailing children problem behaviours and its effects on their knowledge. This may imply that the recommended principles and guidelines for classroom management practices in early childhood education discussed extensively by literature could be compromised. The afore mentioned situation is likely to allow some level of choice for teachers to do as they wish when it comes to problem behaviours of the preschooler. Hence, the need to assess the effects of the behaviours on classroom activities in the Effutu Municipality.

\section{Objectives}

The study sought to examine the prevailing children's problem behaviour and their effects on class activities in pre-schools of the Effutu Municipality. Thus, these objectives were to be achieved by the study:

1. Determine the type of children's problem behaviour prevailing in the pre-schools of the Effutu Municipality

2. Explore the effects of children's problem behaviour on class activities in pre-schools of the Effutu Municipality

\section{E. Research Question:}

These research questions were formulated to guide the study:

1. what type of problem behaviour prevail in the pre-schools of the Effutu Municipality?

2. What is the effect of children's problem behaviour on class activities in the pre-schools of the Effutu Municipality?

\section{METHODOLOGY}

This study employed the convergent design to mixed methods (previously referred to as concurrent triangulation [34]. The concurrent triangulation approach probably being the most familiar of the six major mixed methods models, the researchers employed it to collect both quantitative and qualitative data concurrently intending to compare the two data sets to determine if there was convergence, differences, or some combination. Some authors refer to this comparison as confirmation, disconfirmation, cross validation, or corroboration [35], [36]. The kindergarten teachers of public Basic schools in the Effutu Municipality in Ghana formed the population of this study.

\section{A. Sample and Sampling Techniques}

The study employed stratified sampling, simple random sampling and purposive sampling as a means to get the required sample for the study [37]. Specifically, the sample size for the study was 45 kindergarten teachers. This sample size was selected from 15 schools drawn from three circuits within the Effutu Municipality. Stratified sampling technique was used to aid in the selection of the 15 schools. Simple random sampling was used to select 45 respondents from the 15 selected schools to respond to the questionnaire while purposive sampling was used to sample 15 participants out of the 45 who responded to the questionnaire. The 15 respondents answered the semistructured interview questions designed for the study.

\section{B. Instruments}

A questionnaire and semi-structured interview items were developed by the researchers to gather the relevant data for the study. Specifically, a four-point Likert scale questionnaire with options ranging from: Strongly agree (SA), Agree (A), Disagree (D) to strongly Disagree (SA) was designed to capture a range of responses. Correspondingly, each of those options was rated thus: SA (4), A (3), D (2) and SA (1). For clarity and simplicity, 'Strongly Agree' and 'Agree' were combined as 'Agree' likewise 'Disagree' or 'Strongly Disagree' were combined to represent 'Disagreement'.

\section{Data Collection Procedure}

The consent of the respondents was sort after which they were given time to respond to the questionnaires to the best of their knowledge. The purpose of the study was first explained to them. The researchers interviewed the respondents for about 20 minutes. The interviews were audiotaped and were transcribed for analysis.

\section{Method of Data Analysis}

The researchers used thematic approach to establish meaning from the interview data collected. Morse \& Field [38] explain that thematic analysis involves the search for and identification of common trends that extend throughout an entire interview or set of interviews. The researchers transcribed the tape-recorded interviews, after several readings. The transcribed interviews were then summarized; keeping in mind that more than one theme might exist in a set of interviews. Thus, recorded interviews with related items or ideas were grouped under the same theme. Percentages and frequencies were used as statistical tools to analyse the quantitative data.

\section{DATA ANALYSIS}

This section presents the analysis of quantitative and qualitative data collected from the field in an attempt to achieve the stated research objectives.

\section{$R Q$ 1: What are the types of children's problem behaviour prevailing in the selected pre-schools in the Effutu Municipality?}


TABLE I: TYPES OF CHILDREN'S PROBLEM BEHAVIOUR

\begin{tabular}{|c|c|c|c|c|c|}
\hline \multirow[b]{2}{*}{ Responses } & \multicolumn{2}{|c|}{ Agree } & \multicolumn{2}{|c|}{ Disagree } & \multirow[t]{2}{*}{ MEAN } \\
\hline & $\mathrm{F}$ & $(\%)$ & $\mathrm{F}$ & $(\%)$ & \\
\hline $\begin{array}{l}\text { Children exhibit various } \\
\text { delinquency behaviour in } \\
\text { the early childhood centre }\end{array}$ & 36 & 80 & 9 & 20 & 3.00 \\
\hline $\begin{array}{l}\text { Aggression is a common } \\
\text { problem behaviour } \\
\text { among pre-schoolers. }\end{array}$ & 33 & 73.3 & 12 & 26.7 & 3.04 \\
\hline $\begin{array}{l}\text { Destructiveness is a } \\
\text { prevailing condition } \\
\text { among children in the } \\
\text { pre-school centres }\end{array}$ & 33 & 73.3 & 12 & 26.3 & 3.07 \\
\hline
\end{tabular}

Table 1 shows a description of the responses relating to the views of teachers on the various types of children's problem behaviour. The majority of the respondents $36(80 \%)$ agreed that children exhibit delinquency behaviour in the early childhood centre. The minority of the respondents $9(20 \%)$ disagreed to the statement that children exhibit various problem behaviour in the early childhood centres. A value of $33(73 \%)$ was recorded for aggression, indicating that most of the respondents agreed whiles $12(27 \%)$ disagreed. Relating to destructiveness prevailing among children, a majority of $33(73 \%)$ respondent agreed to that statement, whiles $12(26 \%)$ respondents disagreed.

It could be deduced from the analysed data that, there were various problem behaviours in the early childhood centres, these were related to delinquency, aggression and destructiveness. The following themes emerged from the qualitative data collected, in relation to problem behaviour. The themes were related to threatening and violence behaviour, refusal to take instruction, hyperactivity, wilful destruction of school properties (vandalism).

\section{A. Threatening and violent behaviour}

Among the themes which emerged from qualitative data was threatening and violent behaviour. According to the interview data, respondents were motivated to give the needed information about aggressive behaviour. They were of the view that children's aggression is characterized by threatening attitude which has a serious impact on the classroom activity Respondents were of the view that frightening behaviour among children breeds disruption during learning process and waste of instructional time.

One of the respondents commented:

The children who are strong in the classroom are found fighting the young ones. They even threaten to beat the young ones who will come and tell me the teacher that some boy has beaten them. One girl took another girl's pencil and broke it. Afterwards she threatened to beat her if she decides to inform the teacher. (ECT-5).

Interestingly, the data revealed that, some respondents were of the view that children also display violence act when they are aggressive. They think that children were violent any time they become aggressive. The respondents highlighted that, they felt aggrieved behaviour among children makes them violent even to the extent of damaging items belonging to their peers or the school.

\section{One respondent said: \\ As a teacher, any time I see children fighting one another, they end up destroy items in the classroom. One serious thing about such children is that, they become violent to the level that they damage classroom TLMs, push tables here and there and brake items, (ECT-4).}

The forgoing comments suggest that children become aggressive when violent. It could also be deduced from the data that, children exhibit frightening/threatening behaviour like young child kicks, bites or fights with other children, throw stones, run after another child when it comes to issues aggression.

\section{B. Intentional destruction of property (Vandalism)}

Another major concern that appeared from the interview data was related to respondents experiencing destruction of property within the classroom setting. Firstly, the data suggested that most of the respondents were unhappy because of the multiple destructive activities the children were engaged in. The data revealed that respondents sometimes destroy other children's items like pencil, books, erasers, pushing tables and chairs etc. while teaching and learning were in progress. A respondent shared her experience by saying that:

Most often, I hide behind the scenes with the
intention of observing what will happen in my
classroom. Anytime I do that, I see a lot of
things. Often, I will see that, one of the children
will throw a blackboard ruler at another and it
will fall on the ground and break. In another
scenario, I will see two of the boys fighting one
another and the one who will be beaten then
moves to take anything belonging to the other
boy and destroy it by hitting it on the floor. This
damaging behaviour can happen even when the
teacher is in the classroom. (ECT-8)

Another respondent expressed her frustration thus:

OH! There was a situation, I saw two boys straggling over a school bag So I shouted at them "hey stop", 'hey stop'! 'Hey, stop"! When I got closer to them, one of them said to me that, madam, this girl has torn my book and I have also taken a book from her bag and I want to destroy it. (ECT-1).

Furthermore, a respondent also agreed that, children who are engage in destructive behaviour are found kicking and throwing things. They throw anything that they see within their environment. Some even go to the extent of throwing their school bags and other objects at peers who make them angry without considering what they have in their bags before throwing them at their peers. In this situation, the objects the children throw may be destroyed in the process.

A respondent claimed that:

During break periods at school, I move to see what children do. In the process I saw 
that one of the girls was hit by another and in response the other girl threw her leg to hit the food flask which was containing food and the food in the flask poured out. (ECT-6)

The data presented suggests that, a considerable number of the respondents were of the view that children with destructive behaviour tend to engage in deliberate activities such destroying/damaging peers objects. The data further suggest that, children with destructive behaviour could be seen to intentionally destroy property of others. A comparison of the responses from the questionnaire and the interview reveals that there were some corroborations as well as variations. For example, both interview and questionnaire responses revealed that key among the problem behaviours was aggression and destructiveness. Nevertheless, there were also valuations. For example, delinquency was indicated as a problem behaviour through the questionnaire whereas threatening and violent behaviour and intentional destruction were pointed out through the interview.

\section{Research Question 2: What are the effects of children's problem behaviour on classroom activities}

Table 2 shows a description of the response concerning the effects of children's problem behaviour. The table presents data on the effects of problem behaviour on classroom activity. A total number of $36(80 \%)$ respondents agreed that children with problem behaviour frequently absent than their non-behaviour disordered counterparts whiles $9(20 \%)$ respondents disagreed with this statement. The majority of the respondents $39(87 \%)$ agreed that problem behaviour adversely impacts children's learning, whiles $6(13 \%)$ of the respondents decided to disagree with the statement. Most of the respondents, 30(67\%) agreed that children prove behavioural disorders as well as academic difficulties in elementary school. A few of the respondents $15(33 \%)$ disagreed with this assertion.

Marginal number of respondents totalling 39(87\%) agreed that problem behaviour breeds social exclusion from peers, 6(13\%) respondents disagreed with this statement. About social isolation, 39(87\%) of the respondents agreed to the statement whiles $6(13 \%)$ disagreed with this assertion. Many of the respondents $37(82 \%)$ agreed that problem behaviour increases the likelihood of peers disliking the individual child exhibiting disruptive behaviours, whiles 8 of the respondents representing $17.8 \%$ disagreed with that statement.
TABLE II: THE EFFECTS OF CHILDREN'S PROBLEM BEHAVIOUR

\begin{tabular}{|c|c|c|c|c|c|}
\hline \multirow{2}{*}{ Responses } & \multicolumn{2}{|c|}{ Agree } & \multicolumn{2}{|c|}{ Disagree } & \multirow[t]{2}{*}{ Mean } \\
\hline & $\mathrm{F}$ & $(\%)$ & $\mathrm{F}$ & $(\%)$ & \\
\hline $\begin{array}{l}\text { Children with problem } \\
\text { behaviour frequently } \\
\text { absent and tardy than } \\
\text { their non-behaviour } \\
\text { disordered } \\
\text { counterparts }\end{array}$ & 36 & 80.0 & 9 & 20 & 2.96 \\
\hline $\begin{array}{l}\text { Problem behaviour } \\
\text { adversely impacts } \\
\text { children's learning }\end{array}$ & 39 & 86.7 & 6 & 13.3 & 3.07 \\
\hline $\begin{array}{l}\text { Children with problem } \\
\text { behaviour } \\
\text { demonstrate } \\
\text { behavioural disorders } \\
\text { as well as academic } \\
\text { difficulties in } \\
\text { elementary school }\end{array}$ & 30 & 66.7 & $\begin{array}{l}1 \\
5\end{array}$ & 33.3 & 2.84 \\
\hline $\begin{array}{l}\text { Problem behaviour } \\
\text { breeds social exclusion } \\
\text { from peers }\end{array}$ & 39 & 86.7 & 6 & 13.3 & 3.09 \\
\hline $\begin{array}{l}\text { Extreme cases of } \\
\text { problem behaviour } \\
\text { results in social } \\
\text { isolation for the child. }\end{array}$ & 39 & 86.7 & 6 & 13.3 & 3.09 \\
\hline $\begin{array}{l}\text { Children } \\
\text { behaviour }\end{array} \begin{array}{r}\text { problem } \\
\text { are } \\
\text { associated } \\
\text { more with other } \\
\text { behaviours } \\
\text { aggression, } \\
\begin{array}{l}\text { withdrawal, } \\
\text { distress }\end{array}\end{array}$ & 39 & 86.7 & 6 & 13.3 & 3.27 \\
\hline
\end{tabular}

It could be inferred from the analysis that effects on children's learning, difficulties learning new skills, social exclusion from peers, social isolation from peers, deviant behaviours such as aggression, withdrawal and distress and detrimental effects during adolescence stage were the leading effects of problem behaviour.

Themes relating to the effects of children's problem behaviour were; Disruptive behaviour, isolation from peers, aggressive behaviour.

\section{Disruptive behaviour}

It appeared that, disruptive behaviour was among the related themes of the interviewed data. It seemed from the interview data that, one of the major effects of engaging in problem behaviour was disruption. Firstly, the data from respondents suggested that most children engage in activities which disrupt the class whenever the teacher is teaching. Respondents highlighted that, some of the children make noise with objects that they would be holding to disrupt the attention of those learning.

A respondent claimed that:

During class time, I see some children either playing with objects or drumming with the objects. When this happens, they do not pay attention to what teacher is teaching. Very often, I see a child talking while I am teaching 
and because this child will not be paying attention, when I give exercise at the end of the lesson, he is not able to do it. (ECT-11).

Another respondent added that:

I wonder what some of my children want to do whenever I am teaching them. This particular boy is always looking through the window whenever someone is passing. He does not want to look on the board whenever I am teaching. Anytime I give classwork, he alone will not be able to do it. (ECT-6)

The interview data presented suggested that, children display disruptive attitude during teaching. This negatively affected their participation in academic activities in the classroom.

\section{Isolation from peers}

One of the predominant themes emanated from the interview data was isolation from peers. The interview data revealed that, there was a minimal communication and interpersonal relationship with friends and peers. The interview data from respondents showed that, there was no existing social interaction between the problem child and their friend and peers. One of the respondents commented that:

Oh, for me I want all my class children to do things together. But what I have been seeing is that, the boys are found of bullying the young ones. They do it in the classroom when they are writing their classwork. When it happens like that, the next time you give them work to do together, the whole class will isolate themselves from the one who intimidated their friend. (ECT-2).

The data also suggest that, children with problem behaviour may experience very minimal interaction with their peers. Such children are not able to communicate and mingle with their peers. One respondent expressed her experience that:

I hardly see the whole class talking to a particular girl. Anytime in the classroom, you will see her pushing someone or beating another person. Even during group activity, you will see her insulting others and shouting at them. This make her peers not to interact with her and she alone will be sitting somewhere doing her own thing. (ECT-4).

The responses appear to imply that children with problem behaviour suffer isolation academically. The data further suggest that; children with behaviour problem experience a form of isolation(segregation) from friends.

\section{E. Violent behaviour}

Violent behaviour emerged as one of the themes from the interview According to the interview data, problem behaviour could result in violence. The respondents emphasized that, children problem behaviour was characterised by forceful behaviour. The respondents claimed that, this affected quality classroom practices. A respondent remarked: children in the class becoming violent towards others. Sometime I see them tearing others books. And within the next moment they are breaking pencil which belongs to another person. When I see them in this violence manner, I beat them (ECT-10)

The response suggests that, children with problem behaviour show violent attitude towards peers. Also, it could be deduced that problem behaviour may result in injury. There appears to be a lot of corroborations between the interview responses and that of the questionnaire. Views such as children experiencing behaviour disorders, social isolation and social exclusion were found in both data sets.

\section{DISCUSSIONS}

A. Types of children's problem behaviour prevailing in the pre-schools in the Effutu Municipality

It emerged from the study that, the common children's problem behaviours related to aggression, destructiveness and Intentional destruction of property (Vandalism) [39] argued that coping with, aggressive, destructiveness and Vandalism in the classroom environment is one of the biggest concerns for childcare providers and Head teachers.

In relation to aggression, [40], conducted a study to explore the different types among kindergarten and preschool children in Mohr, Fars province, Iran in 20132014. Findings of the study showed that, the prevalence of aggression is $8-20 \%$ in $3-6$ years old children.Even very young children show features of aggressive behaviour; by eighteen months, children can be observed being physically aggressive toward siblings, peers and adults [41], [42].

Children with aggression exhibit frightening and threatening behaviour like (young child kicks, bites or fights with other children). This has been indeed, supported by a research which has shown that aggressive children are at high risk of later serious and chronic violent behaviour and suggests that there is stability in aggression from adolescence to middle age [18]. The aggressive behaviour syndrome has a childhood onset and is committed to be transitory. It gradually decreases after the early onset, then increases again briefly during mid-adolescence and is resolved by adulthood. Rule breaking behaviour, on the other hand, appears to increase with age [43]

With regard to destructiveness, it emerged that respondents had challenges with their pupils who engaged in such a behaviour. Vylegzhanina et. al. [21], contends that elements of the destructive activity of a person appear in early childhood and the early ages of children destruction could be very close or similar to vandalism. These destructive activities of children affect classroom learning [22]

The analysed data from respondents view children destructive behaviour to intentionally destroying others property. Almost all children engage in these small vandal acts in their communicative environment. Children, whom many authors consider the main perpetrators of destructive, are quite often prone to vandalism actions against a stranger or public property [22]. The available research suggests that, destruction includes intentionally destroying property or any wilful behaviour aimed at destroying, altering, or defacing property belonging to another [31]. Vatova [31] further argued that children with premeditated destructive/vandal behaviours are continually violent or quarrelsome and 
possibly disobedient. They start fighting, pushing, kicking, and or hitting. They throw things, orally threaten classmates and or staff, or destroy property.

\section{B. Effects of children's problem behaviour on classroom activities in the pre-schools of the Effutu Municipality}

In relation to this objective, several themes emerged from the study. It has been revealed that, effects of children's problem behaviour on class activities were; impacts on children's learning, difficulties learning new skills, breeds of social exclusion from peers, and associated deviant behaviour such as aggression, withdrawal, and distress.

To begin with, it emerged from the data that, problem behaviour impacts on children's learning. Firstly, the analyzed data from respondents suggested that most children with problem behaviour engaged in activities which draws their attention from the class activity thereby affecting their academic progress. The data revealed that, children sometimes expressed their emotions in many ways during teaching which calls for the attention of the teacher. This in the end wastes instructional time. The study further revealed that, some of the children make noise with objects that they would be holding to divert the attention of those learning. Also, children exhibit disruptive behaviour which affect their learning in the classroom. It was revealed that some children engage in disruptive activities which impede their participation in academic activities in the classroom. This situation appears to influence and impact on the general academic performance of the children. Other behaviours disrupted children's learning. These include talking out of turn, being out of the seat without permission, not paying attention and distracting other children by making noise or touching them ([15]. It also has been suggested that children exhibiting disruptive behaviours may have difficulties learning new skills [24].

Regnier [28] found that seventh grade children with disruptive behaviour are not only more frequently absent and tardy than their non-behaviour disordered counterparts, but also are less likely to complete their homework and more likely to earn failing grades. Ifeoma, Nkoli, \& Aleke, [45] suggested that children with disruptive behaviour are vulnerable to a host of difficulties during the school years and beyond. They further suggest that, such children are at increased risk for academic and social difficulties, including learning disabilities, peer rejection, and decreased teacher expectations. A child's attention span is a very important factor in the learning process. The amount of time a child spends listening and understanding the teacher affects how much he or she has taken from the lesson [15].

In relation to breeding of social exclusion from peers, the study revealed that, there was a minimal communication and interpersonal relationship with friends and peers. The findings showed that, there was no existing social interaction between the problem child and their friend and peers. It was claimed that, during the play time the problem child will cause trouble for the peers which make the peers unable to include them in the next activity or play time. The information presented suggest that children with problem behaviour suffer isolation academically and isolation (segregation) from friends.
According to [46] research shows that, even infants spend time with peers, and that some three- and four-yearolds are already had trouble being accepted by their peers because early problems with peers had negative consequences for the child's later social and emotional development. Aggressive children are often rejected by their peers, although aggression does not always preclude peer acceptance. It is clear that peer relations pose special challenges to children with conduct disorders and others who lack the emotional, cognitive and behavioural skills that underlie harmonious interaction. The risk for children with early behavioural and emotional problems is exacerbated by the peer rejection they experience.

Shore [47] suggests that, some children are isolated from classmates for a much different reason: their behaviours may turn others off. He further contends that, they may cut in line, talk too much, interrupt conversations, make fun of others, and butt in during games. Not surprising, these children, have trouble making and keeping friends [48]. Literature established that, young children who demonstrate problem behaviours in classrooms, playgroups or other social environments are at risk of a number of later difficulties, including social exclusion from peers, and in some extreme cases, social isolation for the child [49]. As a result, there is an increased likelihood that peers will dislike the individual child exhibiting disruptive behaviours [50].

Concerning the associated deviant behaviours such as aggression, withdrawal, and distress, the study revealed that, children problem behaviour was characterized by forceful behaviour and delinquency. The data claimed that, this affected the quality of children's behaviour. Research suggested that behaviour problems evident in the preschool years were suggestive of future conduct problems, including aggression, antisocial behaviours and juvenile delinquency [51]. As mentioned earlier, children who engage in aggressive behaviours in preschool often are likely to engage in deviant behaviours in middle school; the early onset of aggressive behaviours is the single biggest predictor of future inappropriate and disruptive behaviours and later adult social maladjustment [50]. These findings were supported by [52] that, children with problem behaviour exhibit aggressive and other antisocial behaviour towards peers.

The study further confirmed that, behaviour challenges may result in violent actions (behaviour) and other misbehaviour against others. According to [53] children who display problems with over activity and peers in preschool are likely to be violent and have other future conduct problems through age eight. Moffit [54] found that children who engaged in seriously disruptive behaviour in adolescence, displayed a long-standing history of behaviour problems such as violence.

\section{CONCLUSION}

The study was purported to establish children's problem behaviour and their effect on classroom activities in the early childhood centres of the Effutu Municipality. After the analysis and discussion of findings, it can be concluded that the predominant type of children's problem behaviour related to aggression, destructiveness, threatening and violence, refusal to take instruction/follow rules, and intentional destruction of property. The effects of these behaviour on children were that, they experienced social exclusion from 
their peers, and associated deviant behaviours such as aggression, withdrawal, and distress. Other effects were disruptive, isolation from peers and violent behaviour. Quite obviously, these behaviours would affect their personal learning and classroom activity.

\section{RECOMMENDATIONS OF THE STUDY}

Based on the findings of the study, the researchers recommend that:

The Effutu Municipal Assembly, Winneba Educational Directorate and the headteachers of the sampled schools should organize behaviour guidance and outreach programmes for their teacher on the various types children problem behaviour and educate the teachers on the various aspects of the children behaviour and it corresponding demands. They should also organize field trips to preschool and institutions in the nation to expose teachers to the various early childhood working environment. Additionally, the Municipal Educational Directorate and the headteachers should organize programmes on how to cope, prevent and improve on the effects of children's problem behaviour to ease the burden of parents and teachers. Early childhood education teachers should also make changes to their lesson delivery strategies by asking learners to read out loud, and by actively engaging the supposed disruptive learners more often to improve their concentration and class participation.

\section{REFERENCES}

[1] R. A. Thompson. "Children's perceptions of emotion regulation strategy effectiveness: links with attachment security”, Attachment \& Human Development. 2016, 1-19. PMID 27121493 DOI: 10.1080/14616734.2016.1170051

[2] E. Martinez. "Behaviours that children display in the classroom". GlobalPost. 2014. Retrieved from

http://everydaylife.globalpost.com/behaviours-children-displayclassroom-3335.html on 21/08/2017.

[3] A. Morin. The emotional life of the toddler. New York, NY: The Free Press, 2014.

[4] K. H. Gaskell. "Why do children misbehave in the classroom?", The Bump. 2014. Retrieved., From

http://preschooler.thebump.com/children-misbehave-classroom1216.html on $13 / 10 / 2018$

[5] J. L., Allen, A., Morris \& C. Y. Chhoa. "Callous-unemotional (CU) traits in adolescent boys and response to teacher reward and discipline strategies" Emotional \& Behavioural Difficulties, 2016 21(3), 329-342. doi:10.1080/13632752.2016.1165968

[6] L. J. Keown, M. R. Sanders, N. Franke \& M. Shepherd. “Te Whānau Pou Toru: A randomized controlled trial (RCT) of a culturally adapted lowintensity variant of the Triple P-Positive Parenting Program for Indigenous Māori families in New Zealand" Prevention Science, 2018 , 19, pp. 954-965

[7] R. Goodman, T. Ford, H. Meltzer. "Mental health problems of children in the 38 community: 18 month follow up", BMJ. 2002 Jun 22;32, 4126 (Suppl. 7352):1496-7, 2002

[8] Gomes, L., \& Livesey, D. "Exploring the link between impulsivity and peer relations in 5- and 6-year-old children", Child:care, health and development, 34, 6, 763-770. 2008

[9] Strengthening Transparency, Accountability and Responsiveness, Ghana (STAR-Ghana). "Street children and adolescents in Ghana: A qualitative study of trajectory and behaviour and experience of homelessness", International Journal of Adolescent and Youth, 2013 20(2), pp. 148-150.

[10] A. Harwood-Gross \& M. Lavidor \& Y. Rassovsky. "Reducing aggression with martial arts: A meta-analysis of child and youth studies", Aggression and Violent Behavior. 2017, 34. 10.1016/j.avb.2017.03.001.

[11] T. M. Achenbach. Manual for the teacher's report form and 1991 profile. Burlington, VT: University of Vermont, Department of Psychiatry, 2008.

[12] A. S. Maschi, U. Morgan, K. Bradley \& F. Hatcher. "Training head start teachers in behaviour management using parent-child interaction therapy: A preliminary investigation", Journal of Early and Intensive Behaviour Intervention, 2008, 3, pp. 220-233.

[13] D. S. Shaw \& E. B. Winslow. "Destructive sibling conflict and the development of conduct problems in young boys", Developmental Psychology, 2017, 36(1), pp. 44-53

[14] S. McMahon. Growing up with a single parent. Cambridge, MA: Harvard University PressMoffit, A. (2000). "Developmental models for delinquent behaviour". In S. Hodgins (Ed.), Mental disorders and crime (pp.34). Newbury Park, CA: Sage. 2004

[15] F. D. Hinshaw. "Timing of puberty and reactions to pubertal changes", In Michael Rutter (Ed.), psychosocial disturbances in young people: Challenges form prevention (37 -82). Cambridge: Cambridge University Press, 2007

[16] E. Bradley \& D. Corwyn. "Improving pupil discipline and character". In O.C. Moles (ed.). Student discipline strategies: research and practice. New York State, University of New York Press, 2007

[17] Goddard, M. (2010). Classroom management in secondary schools: A study of student teachers' successful strategies. USA High Beam Research Inc.

[18] O. Perra, \& D. F. Hay. Continuity and change in early angry aggressiveness and prediction of later aggressive conduct problems. Unpublished manuscript. 2016

[19] D. Nagin \& R. Tremblay. Pupils' causal attributions for difficult classroom behaviour. British Journal of Educational Psychology, 2004, 70, pp. 85-96.

[20] O. Kopystynska, K. W. Paschall, M. A. Barnett, M. A Curran. Patterns of interparental conflict, parenting, and child emotional insecurity: A person-centered approach. Journal of Family Psychology, 2017, 31, pp. 922-932. doi:10.1037/fam0000343

[21] A. O. Vylegzhanina, I. V. Vorobyeva, O. V. Kruzhova \& M. Krivoshchekova. "Children's Vandalism: The Problem of Upbringing and Interaction with Family", European Journal of Mental Health 2017, 12, pp. 165-186.

[22], L. A. Smolleck., C. G. Duffy. "The Role of Negative Behavior on Children's Academic Performance in Early Childhood Education", Interdisciplinary Education and Psychology, 2017, 1(1): p. 8.

[23] J. I. Meza, E. B. Owens, S. P. Hinshaw. "Childhood predictors and moderators of lifetime risk of self-harm in girls with and without attention-deficit/hyperactivity disorder", Development and Psychopathology. 2016, 1-17. PMID 32536361 DOI: 10.1017/S0954579420000553

[24] DEC. "How teachers respond to concerns about misbehaviour in their classroom", Psychology in the Schools, 2009, 36(4), pp. 347-358

[25] Y. Finn, E. Pannozzo \& A. Voelkl. "Assessing the influence of maternal depression on the validity of the child behaviour checklist", Journal of Abnormal Child Psychology, 2005, 14, pp. 123-33.

[26] J. M. Thomas, \& K. A. Guskin. "Disruptive behavior in young children: What does it mean?" Journal of the American Academy of Child \& Adolescent Psychiatry, 2001, 40(1), 44-51. https://doi.org/10.1097/00004583-200101000-00015

[27] Thomas, J.M \&Clark, H. "Training preschool children to recruit natural communities of reinforcement", Journal of Applied Behavior Analysis, 2008, 11, pp. 285-303

[28] Regnier, G. (2008). Antisocial behaviour in school: Evidence-based practices (2nd ed.). Belmont, CA: Wadsworth.

[29] McGee, R., Silva, P. A., \& Williams, S. (2004). "Perinatal, neurological, environmental, and developmental characteristics of seven-year-old children with stable behaviour problems". Journal of Child Psychology and Psychiatry, 25, 573-586.

[30] Richman, D. M., Barnard-brak, 1., Laura, G., Bosch, A., \& Abby, L. (2015). "Meta-analysis of noncontingent reinforcement effects on problem behavior", Journal of Applied Behavior Analysis, 48, 131152.

[31] Vatova, Q. "Youth outcomes following implementation of universal swpbis strategies in a Texas secure juvenile facility", Education \& Treatment of Children, 2007 36(3), 135-145.

[32] Filcheck, H. A., \& McNeil, C. B. "The use of token economies in preschool classrooms: Practical and philosophical concerns", Journal of Early and Intensive Behavior Intervention 2004, 1(1), 94-104. http://dx.doi.org/10.1037/h0100281

[33] Gyapong, M., \& Subbey, M. "Nature of children's problem behaviour in kindergarten centres within the Effutu Municipality: the teacher's view", International Journal of Basic Education Research and Policy, 20192(1), 57-61.

[34] Creswell, J. W., \& Piano Clark, V. L. Designing mixed methods research. ( $2^{\text {nd }}$ ed.). 2011

[35] Greene, C.J., Valerie J. Caracelli, J.V., \& Graham, F.W. "Toward a Conceptual Framework for Mixed-Method Evaluation Designs" Educational Evaluation and Policy Analysis, 1989, 11(3), pp. 255-274. 
[36] Morgan, D. L. "Practical strategies for combining qualitative and quantitative methods" Thousand Oaks, CA: Sage 1998

[37] Cohen, F., Manion, E., \& Morrison, G. "Combined qualitative and quantitative approach" In A. S. De Vos, H. Strydom, C. B. Fouche, \& C. L. Delport, Research at grass roots for social sciences and human service professions. (pp, 56). Pretoria: Van Schaik. 2011

[38] Morse, J. M., \& Field P. "Nursing Research, the application of qualitative approaches", Thousand Oaks, California: SAGE publication. 2006

[39] Kupersmidt, J. B., Bryant, D., Willoughby, M.T., \& Vizzard, R. "Prevalence of aggressive behaviour among preschoolers in head start and community childcare programs" Behavioural Disorders, 2009, 26 , 42-52.

[40] Anderson, D. "Making teachers accountable for students' disruptive classroom behaviour", British Journal of Sociology of Education, 200023(1), 107-122.

[41] Keenan, F., \& Wakschlag, E. "Understanding and managing student's problem behaviour in schools: An integrative approach" Education Journal, 2000, 24(2), pp. 15-28.

[42] Tremblay, R.E. "Social and emotional learning in schools: From programs to strategies", Society for Research in Child Development Social Policy Report, 2004, 26(4), 4-15.

[43] Niv, S., Tuvblad, C., Raine, Raine, A., \& Baker, L. "Aggression and Rule-breaking: Heritability and stability of antisocial behavior problems in childhood and adolescence", Journal of Criminal Justice. 41. 10.1016/j.jcrimjus.2013.06.014.

[44] Hinshaw, S. P. "Preadolescent girls with attention-deficit/hyperactivity disorder: I. Background characteristics, comorbidity, cognitive and social functioning, and parenting practices", Journal of Consulting and Clinical Psychology, 2002, 70(5), 1086-1098. https://doi.org/10.1037/0022-006X.70.5.1086

[45] Ifeoma, B., Nkoli, E., \& Aleke, D. "Disruptive classroom behaviours among primary school pupils: intervention imperative", Ideal Journal of Education and Policy Studies, 2016 2(2), pp. 86-91.

[46] Grusec, J., Danyliuk, T., \& Kil, H., \& O’Neill, D. "Perspectives on parent discipline and child outcomes", International Journal of Behavioral Development. 41. 2017016502541668153. $10.1177 / 0165025416681538$

[47] Shore, D. Theories of development concepts and application. Upper Saddle River, NJ: Prentice-Hall, 2016a

[48] Kenneth, D. \& Shore, B. "Prevention strategies for at-risk students and students with EBD in elementary schools", Journal of Emotional and Behavioural Disorders, 2016, 7(3), 178-188.

[49] McClellan, J. The Incredible years parent, teacher, and child intervention: Targeting multiple areas of risk for a young child with pervasive conduct problems using a flexible, annualized, treatment program. Journal of Cognitive and Behaviour Practice, 2007, 8, pp. $377-386$

[50] Hartup, J., \& Moore, R. "The assessment of depression in the postnata period: a comparison of four self-report questionnaires", Australian and New Zealand Journal of Psychiatry, 2000, 31,353-.355.

[51] Masse, H \& Tremblay, R.E. "Social and emotional learning in schools: From programs to strategies", Society for Research in Child Development Social Policy Report, 2009 26(4), pp. 4-15.

[52] Conner, D. G. (2001). Characteristics of adolescents Charged with homicide: Review of 72 cases. Behavioural Sciences and the Law, 5 , $11-23$

[53] Richman, D. M., Barnard-brak, 1., Laura, G., Bosch, A., \& Abby, L. Meta-analysis of noncontingent reinforcement effects on problem behavior. Journal of Applied Behavior Analysis, 2002, 48, 131-152.

[54] Moffitt T. E. "E-Risk Study Team Teen-aged mothers in contemporary Britain". Journal of Child Psychology and Psychiatry; 2000, 43, pp. $727-742$

S. Oppong Frimpong is an experienced university teacher with more than a decade teaching experience at a higher institution. Oppong Frimpong was born in Ashanti Region of Ghana. He holds Doctor of Philosophy (in early childhood education) from University of Aberdeen in Scotland, UK and completed in 2017. Oppong Frimpong also holds Master of Philosophy (in educational psychology) from University of Cape Coast in Ghana and completed in 2005 .

He has a number of publications to his credit. Some of them have been listed below:

Oppong Frimpong, S. (2020). Assessing the quality of ECE teachers in Ghana: Juxtaposing theory to practice. European Journal of Education Studies. Volume 7 Issue 12 . Doi.org/10.46827/ejes.v7i12.3505

Oppong Frimpong, S. \& Osei, D. (2020). Socio-emotional development of the kindergarten pupil: the role of assessment in the Kumasi
Metropolis, Ghana. European Journal of Education Studies. Volume 7 Issue 12 | Doi.org/10.46827/ejes.v7i12.3505

Oppong Frimpong, S. (2019). The classroom physical environment as a

"third teacher" for an early childhood education provision in the Ga-

West Municipality of Ghana. International Journal of Social Sciences,

4(3), 1339-1360.

$\mathrm{He}$ is a researcher interested in child growth and development, observation and assessment of the young child, interaction in Early childhood Education, creating a developmentally appropriate environment for Early childhood Education provision and issues on child safety and wellbeing at the early childhood centre. Oppong Frimpong is currently a Senior Lecturer with the Department of Early Childhood Education in the University of Education, Winneba in Ghana.

Dr. Samuel is a member of University Teachers Association of Ghana (University of Education, Winneba Branch) and a member of Ghana Psychological Council. He has held numerous positions and served on a number of committees. Positions held include:

Acting Head of Department, Department of Early Childhood Education, University of Education, Winneba; Faculty of Educational Studies (FES) representative on the University of Education, Winneba's Publications Board and currently the Co-ordinator for Supported Teaching in Schools for University of Education, Winneba and all the Affiliate Institutions, including Colleges of Education for University of Education, Winneba in Ghana. Some of the committees served on include being a Member of the Academic Board, University of Education, Winneba; Member of the National Team writing the Course Manual for Bachelor's Degree in the Colleges of Education (Early Grade Specialism) in Ghana and a Member of the National Team writing the Curriculum for Bachelor's Degree in the Colleges of Education (Early Grade Specialism.

M. Gyapong was born in the Western Region of Ghana. Gyapong holds Master of Philosophy (in early childhood education) from University of Education, Winneba, Ghana. He completed in that programme in 2018 Gyapong also holds Bachelor of Education (in early childhood education) from the same university completing in 2011

Mark is a young researcher who is interested in Early Childhood Literacy, Child behaviour management and developmentally appropriate early childhood education.

Mark is a member of University Teachers Association of Ghana (University of Education, Winneba Branch). He is currently the Examinations Officer for the Department of Early Childhood Education, University of Education, Winneba 
